\title{
Screening and Differential Diagnosis of Renal Light Chain-Associated Diseases
}

\author{
Jens Gerth ${ }^{a}$ Anja Sachse ${ }^{a}$ Martin Busch ${ }^{b} \quad$ Nico Illner $^{a} \quad$ Lars-Olof Muegge $^{b}$ \\ Hermann-Josef Grönec Gunter Wolf ${ }^{\mathrm{b}}$ \\ ${ }^{a}$ Department of Internal Medicine II, Heinrich Braun Klinikum Zwickau, Zwickau, ${ }^{b}$ Department of Internal Medicine III, \\ University of Jena, Jena, and ' Department of Cellular and Molecular Pathology, German Cancer Research Center, \\ Heidelberg, Germany
}

\section{Key Words}

Light chain diseases $\cdot$ Urine protein profile $\cdot$ Myeloma cast nephropathy $\cdot$ Amyloidosis $\cdot$ Monoclonal immune deposition disease

\begin{abstract}
Background: Renal involvement in the light chain-associated diseases multiple myeloma (MM), amyloidosis (AL) and monoclonal immune position disease (MIDD) is common and differential diagnosis usually requires renal biopsy. The aim of this study was to investigate if noninvasive methods are viable to identify and differentiate between the various types of kidney diseases. Patients and Methods: All patients with a light chain-associated disease admitted to our center from 1996 to 2008 were retrospectively evaluated. Renal biopsy data were correlated with proteinuria findings. Results: Only the ratio of free $\kappa / \lambda$ light chains showed a good sensitivity for myeloma cast nephropathy (MCN), AL and MIDD. The $\lambda$ light chain was characteristic for $A L$, the $\kappa$ light chain dominated in MIDD. Renal function at the time of diagnosis was worst in MIDD. MCN presented with a proteinuria of $>3.5 \mathrm{~g} / \mathrm{g}$ creatinine. In contrast, a higher proteinuria was found in AL or MIDD. Whereas the $\kappa / \lambda$ ratio in the urine was pathological for all three diseases, extremely high or low ra-
\end{abstract}

tios indicated the presence of MCN. However, in AL or MIDD, the ratio was only moderately elevated. Conclusion: A noninvasive differentiation between $\mathrm{MCN}$ and other forms of renal light chain disease is possible.

Copyright $\odot 2011$ S. Karger AG, Basel

\section{Introduction}

Not uncommonly, diagnostic efforts to differentiate the causes of proteinuria lead to the diagnosis of multiple myeloma (MM) in elderly patients. In up to $40 \%$ of patients, the diagnosis is first made by renal biopsy [1]. About $20-50 \%$ of MM patients present with impaired renal function when first diagnosed [2,3]. Up to $80 \%$ of these patients show a proteinuria in the pathologic range, usually caused by light chains (Bence-Jones proteinuria). A proteinuria of $\geq 3.5 \mathrm{~g} /$ day has been commonly found in $15-20 \%$ of MM patients $[2,4,5]$. The differential diagnosis of an impaired renal function in $\mathrm{MM}$ is complex and includes, besides the 'classical' myeloma cast nephropathy (MCN), also amyloidosis (AL) and monoclonal immune position disease (MIDD).

It has been assumed that the renal manifestations of light chain diseases cannot easily be differentiated by

\section{KARGER \\ Fax +4161306 1234 E-Mail karger@karger.ch} www.karger.com (c) 2011 S. Karger AG, Basel

$1420-4096 / 12 / 0352-0120 \$ 38.00 / 0$

Accessible online at:

www.karger.com/kbr
Gunter Wolf, MD, MHBA

Klinik für Innere Medizin III, University of Jena

Erlanger Allee 101, DE-07347 Jena (Germany)

Tel. +4936419324301

E-Mail Gunter.Wolf@med.uni-jena.de 


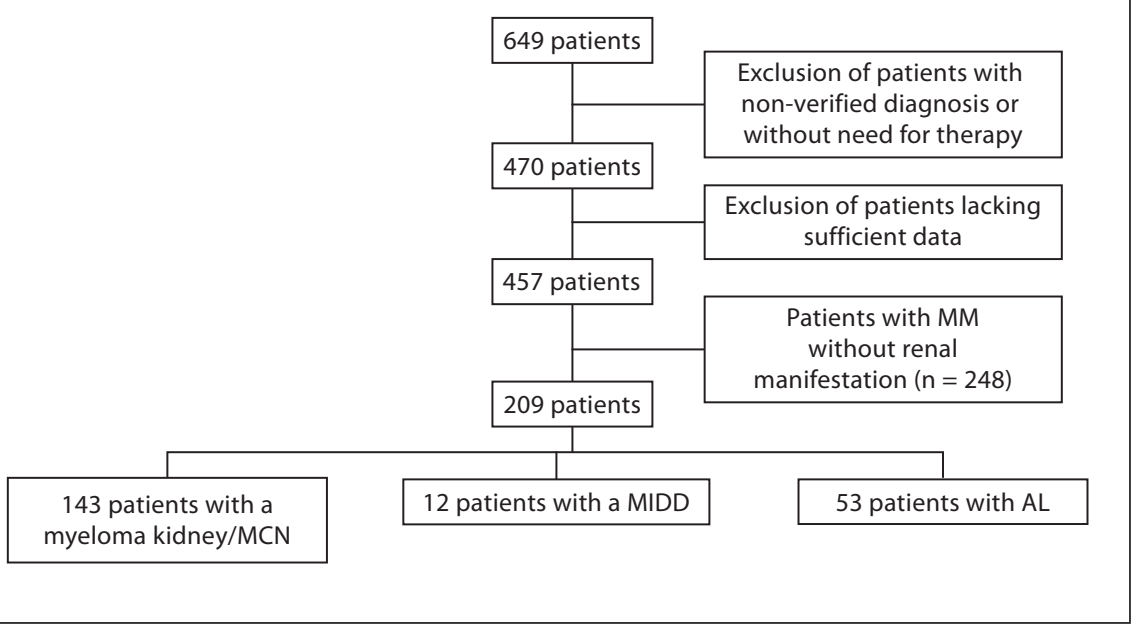

Fig. 1. Analysis of included patients.

noninvasive means [6]. Autopsy studies in MM have found MCN in $30-50 \%$, AL in $4-5 \%$ and MIDD in $2-3 \%$ $[7,8]$. The correct renal diagnosis is crucial for further treatment. Until now, it has been generally believed that MCN, AL or MIDD can only be identified by renal biopsy.

The production of a monoclonal immune globulin or an immune globulin fragment is crucial in the development of a renal manifestation in MM. In healthy kidneys, a surplus of light chains is filtered in the glomerulus and reabsorbed in the tubules without resulting in renal injury. Only monoclonal light chains (and their fragments) are capable of damaging the kidney $[9,10]$. Furthermore, experimental designs have shown that injection of monoclonal proteins derived from patients with a MCN, a MIDD, or an AL into animals induced renal damage reminiscent of the renal disease of the human donor. It was consequently concluded that structural abnormalities of the monoclonal molecules are responsible for the specific forms of renal manifestation [9-12]. Although modern biopsy techniques such as ultrasound guidance and semiautomatic biopsy guns have been established, the risk of bleeding exists in MM because thrombocytopenia is frequently present, and abnormalities of the coagulation system exist due to the nephrotic syndrome and high levels of paraproteins [13].

Since only few data exist concerning screening methods for light chain diseases with renal involvement as well as for the differential diagnosis of monoclonal disease, it was the aim of this study to find out whether noninvasive means are viable to indentify and differentiate between the various types of manifestations of light chain-associated kidney diseases.

Myeloma and Kidney

\section{Patients and Methods}

This study was a retrospective analysis of all patients with a monoclonal light chain-associated kidney disease who were diagnosed and treated at the Friedrich Schiller University in Jena, Germany, between 1996 and 2008. We included all patients with MM in stages II or III according to the classification of Durie and Salmon [14], or with a monoclonal gammopathy of undetermined significance with renal impairment due to monoclonal proteins. Moreover, all patients with the histological diagnosis of AL or MIDD were included. After excluding patients who did not undergo any specific treatment and those without a sufficient set of data, 470 patients with MM were analyzed (fig. 1). Out of these 470 patients, 209 were found to have renal involvement, defined as either a histologically proven renal disease or an impaired renal function in combination with a Bence-Jones proteinuria, or a Bence-Jones proteinuria $>1 \mathrm{~g} /$ day, while normal kidney function was demonstrated. An impaired kidney function was defined as an estimated glomerular filtration rate (eGFR) $<90 \mathrm{ml} / \mathrm{min} /$ $1.73 \mathrm{~m}^{2}$ using the MDRD equation 7 formula [15].

In addition to the data concerning the exact renal diagnosis, the histological description of organ tissues (e.g. kidney, liver, heart) and an extensive set of laboratory data were analyzed. We used a stepwise process and first derived clinical parameters from patients with histologically proven MCN before using this set of parameters for all patients. Special emphasis was given to parameters expected to help differentiating between the manifestations of renal damage in light chain diseases.

Only patients with a histological confirmation of the diagnosis were considered for the analysis of screening parameters for light chain diseases and the differential diagnosis between the different kinds of renal involvement. These included 144 patients with $\mathrm{MCN}, 53$ with AL, and 12 with MIDD.

The decision to carry out a tissue biopsy was made according to clinical indications. The number of biopsies and the kind of tissue that was examined are shown in table 1. Renal biopsies were exclusively examined by Prof. Dr. H.-J. Gröne (German Cancer Research Center, Heidelberg, Germany). Other tissues (except 
myocardial biopsies, which were sent to Prof. Dr. G. Mall, Darmstadt, Germany) were evaluated at the local pathological institute in Jena or, in some cases, sent to national reference laboratories for a second opinion.

\section{Statistical Evaluation}

Data are shown as means \pm SD. A p value $<0.05$ was considered significant. When comparing two groups with normally distributed data, the $\mathrm{T}$ test for independent or paired random samples was used. The nonparametric Kruskal-Wallis test was used for comparison of several groups with at least one group that was non-normally distributed. To compare the mean values of two non-normally distributed groups, the nonparametric MannWhitney test for independent random samples and the Wilcoxon test for paired random samples were applied. To examine a possible connection or a significant difference between two or more nominal parameters, cross tables were generated, and Fisher's exact test was used to determine the significance level. Uni- and multivariate logistic regressions were used for selected analyses.

\section{Results}

Using the histological and nonhistological criteria mentioned below, 144 patients with MCN, 53 patients with AL and 12 patients with MIDD were evaluated. The baseline parameters of the studied patients are found in table 2. In $45.3 \%$ of all 474 patients with a light chain disease, a renal impairment as defined above was present at the time of first diagnosis. Table 3 shows the incidence of renal impairment in MM, AL and MIDD patients, respectively. The absolute numbers of renal impairment are illustrated in figure 2 . The majority of patients had MCN (68\%). In only 25 and $6 \%$ of patients, AL or MIDD was diagnosed. $18.9 \%$ of all patients had diabetes mellitus at the time of diagnosis of light chain disease defined by a fasting plasma glucose $\geq 7.0 \mathrm{mmol} / \mathrm{l}$ or 2 -hour plasma glucose $\geq 11.1 \mathrm{mmol} / 1$ (according to the WHO criteria). Moreover, $12.2 \%$ of patients suffered from hypertension (defined by a systolic blood pressure $>140$ and/or a diastolic pressure $>90 \mathrm{~mm} \mathrm{Hg}$ ). $47.5 \%$ of these patients received an angiotensin-converting enzyme inhibitor whereas $14.2 \%$ were treated with an AT1 receptor antagonist, and $7.35 \%$ with a combination of both drugs.

At the time of diagnosis, $15.9 \%$ of MCN patients received chemotherapy whereas only 1 patient $(2.6 \%)$ of the AL patients received therapy at the time of diagnosis. In addition, only 1 patient of the MIDD group was treated with chemotherapy at the time of renal diagnosis. There was no significant difference in laboratory parameters in the MCN group with and without chemotherapy.

Renal function differed between the patients of light chain diseases (fig. 3). Patients with MIDD had a more
Table 1. Histological findings in patients with a light chain disease

\begin{tabular}{llc}
\hline & $\begin{array}{l}\text { Histologically } \\
\text { verified cases, } \mathrm{n}\end{array}$ & $\begin{array}{l}\% \text { of } \\
\text { patients }\end{array}$ \\
\hline MCN ( $\mathrm{n}=144)$ & 32 & 22.4 \\
Light chain nephropathy $(\mathrm{n}=12)$ & 12 & 100 \\
AL $(\mathrm{n}=53)$ & $51^{\mathrm{a}}$ & 98.1 \\
Renal biopsies & 37 & 69.8 \\
Myocardial biopsies & 6 & 11.3 \\
Gastrointestinal biopsies & 4 & 7.6 \\
Lung biopsies & 1 & 1.9 \\
Skin biopsies & 1 & 1.9 \\
Lymph node biopsies & 2 & 3.8 \\
\hline
\end{tabular}

${ }^{a}$ In 2 patients the diagnosis was verified postmortem.

Table 2. Age and body mass index (BMI) of MCN, AL and MIDD patients (mean $\pm \mathrm{SD})$

$\begin{array}{llll}\begin{array}{l}\text { MCN } \\ (n=144)\end{array} & \begin{array}{l}\text { AL } \\ (n=53)\end{array} & \begin{array}{l}\text { MIDD } \\ (n=12)\end{array} & p\end{array}$

$\begin{array}{cllll}\begin{array}{c}\text { BMI at time of first } \\ \text { diagnosis }\end{array} & 26.3 \pm 4.2 & 26.3 \pm 4.8 & 27.9 \pm 3.3 & 0.08^{\mathrm{a}} \\ \begin{array}{c}\text { Age at time of first } \\ \text { diagnosis, years }\end{array} & 64.8 \pm 11.6 & 62.5 \pm 9.1 & 64.4 \pm 8.4 & 0.13^{\mathrm{a}} \\ \begin{array}{c}\text { \% male patients } \\ \text { male }\end{array} & 64.3 & 58.5 & 58.3 & 0.31^{\mathrm{b}}\end{array}$

a Significance according to the non-parametric Kruskal-Wallis test.

b Significance according to Fisher's exact test.

Table 3. Renal impairment in patients with light chain disease at the time of diagnosis

\begin{tabular}{lllll}
\hline & $\begin{array}{l}\mathrm{MM} \\
(\mathrm{n}=474)\end{array}$ & $\begin{array}{l}\mathrm{AL} \\
(\mathrm{n}=53)\end{array}$ & $\begin{array}{l}\text { MIDD } \\
(\mathrm{n}=12)\end{array}$ & $\mathrm{p}^{\mathrm{a}}$ \\
\hline $\begin{array}{c}\text { \% of patients with } \\
\text { renal impairment }\end{array}$ & 45.8 & 90.6 & 100 & $<0.001$ \\
\hline
\end{tabular}

a Significance according to Fisher's exact test.

impaired renal function than patients with $\mathrm{MCN}$ and $\mathrm{AL}$ (table 3).

This study compares the sensitivity of noninvasive diagnostic methods to differentiate between MCN, AL, and MIDD. Renal function at the time of diagnosis differed significantly between the patients, according to the type of light chain disease (fig. 3). 
Fig. 2. Diagnosis in patients with a light chain disease and renal impairment.

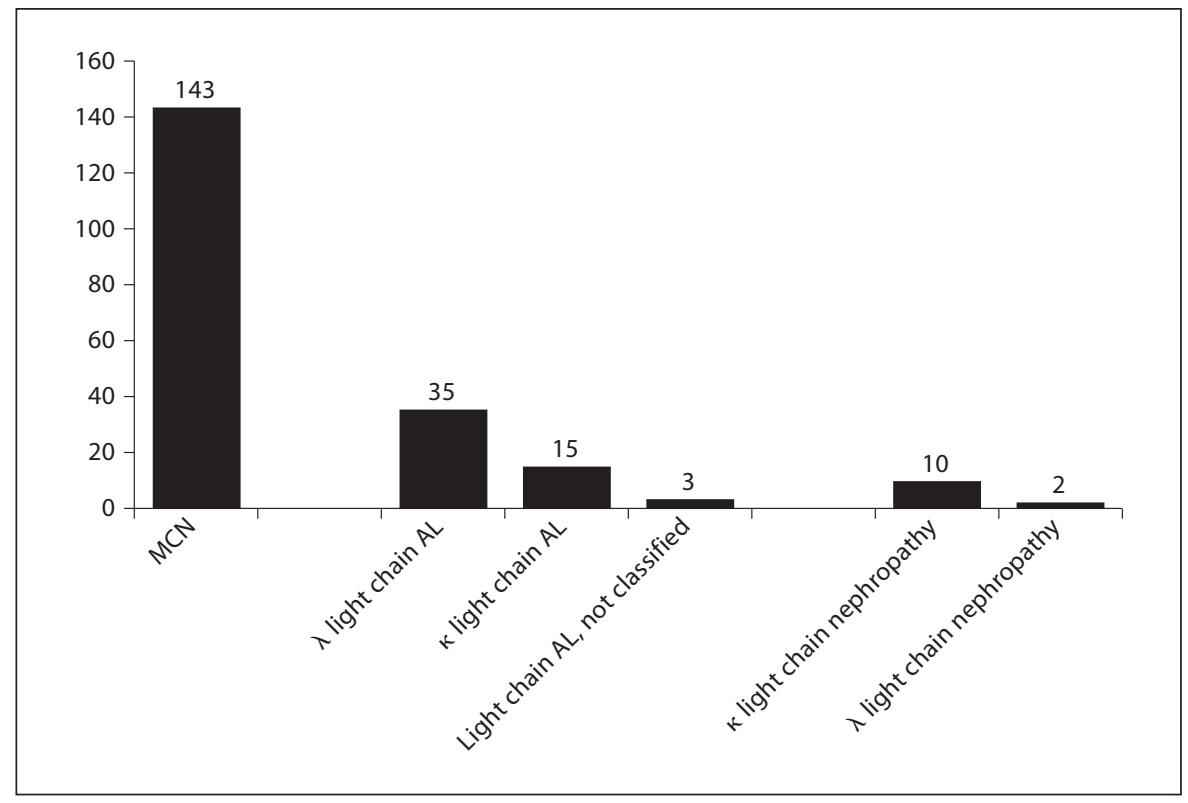

Table 4. Sensitivities of various parameters to detect a monoclonal gammopathy

\begin{tabular}{lcccc}
\hline \% of patients with a positive & MCN & AL & MIDD & $p^{\mathrm{a}}$ \\
\hline $\begin{array}{l}\text { Extra gradient in serum } \\
\quad \text { protein electrophoresis }\end{array}$ & 87.3 & 35.3 & 41.7 & $<0.001$ \\
Serum immunofixation & 97.9 & 64.2 & 58.3 & $<0.001$ \\
Urine immunofixation & 96.4 & 76.9 & 55.6 & $<0.001$ \\
Immunofixation in serum or urine & 100 & 85 & 77.8 & $<0.001$ \\
Light chain ratio in serum & 90.6 & 51.1 & 63.6 & $<0.001$ \\
Light chain ratio in urine & 92.9 & 85.1 & 54.5 & 0.001 \\
Ratio of free light chains in serum & 96.8 & 100 & 71.4 & 0.036 \\
\hline
\end{tabular}

a According to Fisher's exact test.

It was found that in patients with MCN, all methods with the exception of protein electrophoresis had a sensitivity of $>90 \%$ (table 4 ). As shown in table 5 we found a significant $(p<0.05)$ negative correlation of $\lambda$ light chain in serum and urine, but not $\kappa$ light chain concentrations or $\kappa / \lambda$ ratios and renal function as defined by eGFR. However, protein electrophoresis, immunofixation in serum and in urine, and the $\kappa / \lambda$ light chain ratio in serum and urine were not sufficiently sensitive to differentiate between the diseases in those patients with either AL or MIDD. The light chain ratio in urine showed good sensitivity in the AL group (85.1\%), but performed poorly in patients with MIDD (sensitivity 54.5\%; table 4).

Myeloma and Kidney

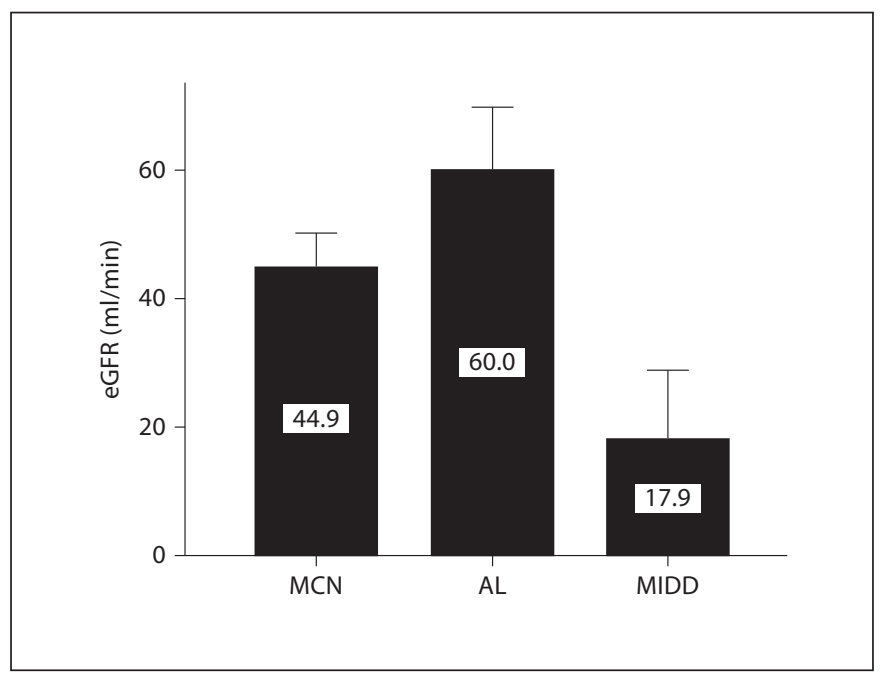

Fig. 3. eGFR at the time of diagnosis depending on the renal diagnosis. $\mathrm{p}<0.001$ (ANOVA).

A combination of parameters may solve this problem. In patients with $\mathrm{AL}$ as well as MIDD, the combination of the parameters 'immunofixation in the serum' or 'immunofixation in the urine' yields a sensitivity of 85 and $77.8 \%$, respectively. However, the best sensitivity was seen with the ratio of the free light chains in the serum using the 'free light test'. A sensitivity of $100 \%$ was found in 20 patients of the AL group. For the MIDD group, the sensitivity was $71.4 \%$, but only 7 MIDD patients were tested

Kidney Blood Press Res 2012;35:120-128 
Table 5. Correlations between serum/urinary light chain concentrations and renal function (eGFR)

\begin{tabular}{|c|c|c|c|c|c|c|c|c|c|}
\hline & $\begin{array}{l}\kappa \text { light } \\
\text { chains, } g / 1\end{array}$ & $\begin{array}{l}\lambda \text { light } \\
\text { chains, } g / 1\end{array}$ & $\begin{array}{l}\text { Ratio } \\
\kappa / \lambda\end{array}$ & $\begin{array}{l}\text { Free } \kappa \text { light } \\
\text { chains, } g / 1\end{array}$ & $\begin{array}{l}\text { Free } \lambda \text { light } \\
\text { chains, } g / 1\end{array}$ & $\begin{array}{l}\text { Ratio of } \\
\text { free } \kappa / \lambda\end{array}$ & $\begin{array}{l}\kappa \text { urinary light } \\
\text { chains, } g / l\end{array}$ & $\begin{array}{l}\lambda \text { urinary light } \\
\text { chains, } g / 1\end{array}$ & $\begin{array}{l}\text { Urinary } \\
\text { ratio } \kappa / \lambda\end{array}$ \\
\hline Pearson correlation & 0.119 & $-0.185^{\mathrm{a}}$ & -0.015 & -0.123 & -0.295 & -0.132 & -0.014 & $-0.202^{\mathrm{a}}$ & -0.035 \\
\hline Significance (2-tailed) & 0.165 & 0.031 & 0.859 & 0.510 & 0.107 & 0.479 & 0.873 & 0.017 & 0.685 \\
\hline Number & 137 & 137 & 137 & 31 & 31 & 31 & 139 & 139 & 139 \\
\hline
\end{tabular}

${ }^{\text {a }}$ Correlation is significant at the 0.05 level (2-tailed).

Table 6. Standard parameters for follow-up in patients with a light chain diseases (mean \pm SD)

\begin{tabular}{lcccc}
\hline & MCN & AL & MIDD & p \\
\hline Calcium in serum, mmol/l & $2.45 \pm 0.44$ & $2.24 \pm 0.19$ & $2.15 \pm 0.23$ & $<0.001^{*}$ \\
Hypocalcemia, \% & 29.1 & 3.8 & 0 & $<0.001^{* *}$ \\
Serum protein, g/l & $83.5 \pm 19.9$ & $55.6 \pm 12.6$ & $70.9 \pm 18.5$ & $<0.001^{*}$ \\
Serum albumin, g/l & $35.4 \pm 8.3$ & $26.2 \pm 10.5$ & $33.9 \pm 4.0$ & $<0.001^{*}$ \\
Serum cholesterol, mmol/l & $4.9 \pm 1.4$ & $7.9 \pm 5.1$ & $5.1 \pm 1.4$ & $<0.001^{*}$ \\
Erythrocyte sedimentation rate after $1 \mathrm{~h}, \mathrm{~mm}$ & $75.2 \pm 36.2$ & $48.6 \pm 28.8$ & $65.5 \pm 36.6$ & $0.001^{*}$ \\
C-reactive protein, mg/l & $24.4 \pm 50.3$ & $11.3 \pm 31.4$ & $22.9 \pm 20.4$ & $<0.001^{*}$ \\
Uric acid, $\mu$ mol/l & $437.3 \pm 148.2$ & $449.9 \pm 135.2$ & $381.2 \pm 101.8$ & $0.190^{*}$ \\
Lactate dehydrogenase, $\mu$ mol/l & $4.2 \pm 2.5$ & $4.2 \pm 1.5$ & $3.5 \pm 1.0$ & $0.330^{*}$ \\
Serum $\alpha_{2}$-microglobulin, mg/l & $12.2 \pm 11.7$ & $5.4 \pm 4.7$ & $12.2 \pm 8.0$ & $0.001^{*}$ \\
Plasma viscosity, mPa·s & $1.5 \pm 0.6$ & $1.2 \pm 9.2$ & $1.8 \pm 1.7$ & $0.001^{*}$ \\
Clinical apparent hyperviscosity syndrome, \% & 15.8 & 0 & 9.1 & $0.025^{* *}$ \\
\hline
\end{tabular}

* According to the non-parametric Kruskal-Wallis test.

** According to Fisher's exact test.

with the 'free light test' since it had only been available more recently.

The mean values of the standard parameters that are commonly used as a control for light chain diseases are found in table 6. Patients with MCN exhibited a significantly higher serum calcium level, erythrocyte sedimentation rate, serum protein, and serum albumin and Creactive protein concentration. Significantly more patients in the MCN group were hypercalcemic at the time of diagnosis. Patients with AL had, compared to the MCN or MIDD patients, a lower serum calcium, serum protein, serum albumin, erythrocyte sedimentation rate, C-reactive protein, serum $\beta_{2}$-microglobulin, and plasma viscosity. No difference was found between the two groups concerning uric acid and lactate dehydrogenase.

The extent of urinary protein excretion (fig. 4a) differed markedly according to the particular light chain disease. Patients with MCN had the least amount of pro- tein in their urinary samples. To differentiate between the different kinds of renal impairment with the help of the specific urine protein analyses was one of the major goals of the study. Most of the patients with MCN (96.4\%) as well as those with AL (76.9\%) presented with a positive immunofixation in their urinary samples, whereas this was true in only $55.6 \%$ of the patients with MIDD ( $p<$ 0.001 , Fisher's exact test). Similar results were verified when considering the quotient of $\kappa$ and $\lambda$ light chains in the urinary samples (positive results in 92.9, 85.1, and $54.5 \%$ of MCN, AL and MIDD patients, respectively, $\mathrm{p}=$ 0.001 , Fisher's exact test).

The light chain ratios in the urinary samples of $\mathrm{MCN}$ patients significantly differed when compared to those of $\mathrm{AL}$ and MIDD patients (fig. $4 \mathrm{~b}, \mathrm{c}$ ). The light chain quotients in the urinary samples of MCN patients were significantly different compared to those of AL and MIDD patients (fig. 4b, c). MCN could be easily differentiated by 

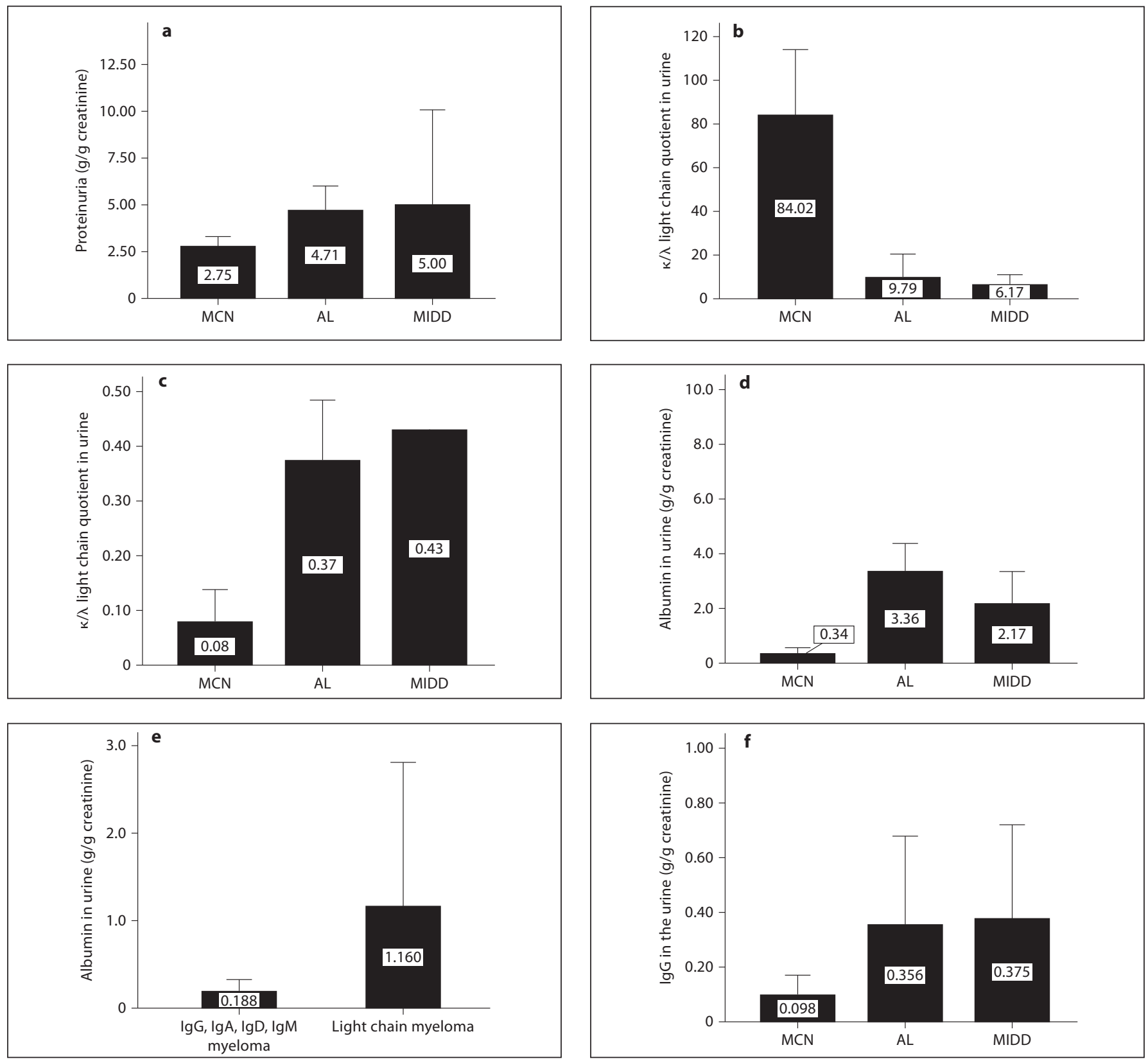

Fig. 4. a-g Proteinuria findings. a Total proteinuria depending on the kind of renal involvement ( $p=0.001$, Kruskal-Wallis test). b, $\mathbf{c} \kappa / \lambda$ ratio in the urine. b Patients with a monoclonal light chain $\kappa(p=0.036$, Kruskal-Wallis test). c Patients with a monoclonal light chain $\lambda(p<0.001)$. d Albuminuria $(p<0.001$, Kruskal-Wallis test). e Albuminuria in the group of MCN patients, depending on the presence of a complete monoclonal immune globulin versus a light chain myeloma ( $p=0.376$ according to the Mann-Whitney test). f Urinary IgG ( $\mathrm{p}<0.001$, Kruskal-Wallis test). $\mathbf{g} \alpha_{1}$-Microglobulin ( $\mathrm{p}=0.02$, Kruskal-Wallis test).

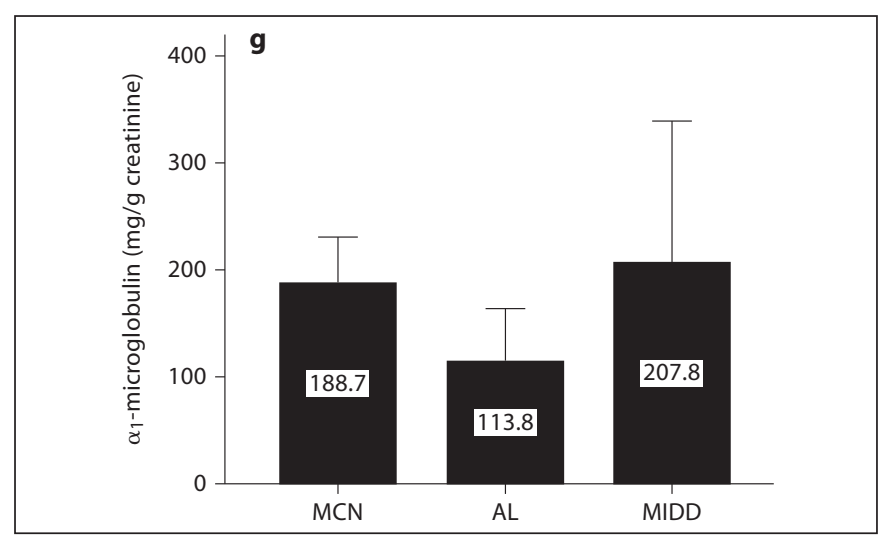


a very high or a very low ratio of light chains. According to a ROC curve of the $\kappa / \lambda$ light chain ratio, a cut-off of 19.9 for MCN type $\kappa$ could be determined in comparison to AL and MIDD (specificity 90\%). The cut-off for MCN type $\lambda$ was 0.18 for the same specificity.

The albumin concentration in the urine was lowest in the group of MCN (fig. 4d). In AL or MIDD, the albuminuria was moderately elevated (3.6 and $2.2 \mathrm{~g} / \mathrm{g}$ creatinine, respectively). When discriminating between $\mathrm{MCN}$ with an immune globulin myeloma and MCN with a light chain myeloma, the latter group showed a higher albuminuria (fig. 4e). The urinary IgG concentration was also characteristic and showed a moderately elevated excretion in AL or MIDD (fig. 4f). The excretion of $\alpha_{1}$-microglobulin in the urine as a marker of tubular proteinuria was pathologically elevated in all groups (fig. 4g); however, it was significantly lower in AL. A difference within the MCN group between patients with a light chain myeloma and an immune globulin myeloma could not be found.

In some patients, an erythrocyturia was noted at the time of diagnosis. This was seen significantly more often in MIDD (58.3\%) in comparison to MCN (18.7\%) or AL $(17.0 \%)(\mathrm{p}=0.019$, Fisher's exact test).

Univariate Cox regression showed no significant correlation between the concentrations of light chains or the ratios and mortality (data not shown). However, for the further subsequent development of end-stage renal disease a significant correlation was only found for $\lambda$ light chains (MCN, AL, MIDD groups, data from 33 patients, $\mathrm{p}=0.028$, hazard ratio 2.3 , univariate logistic regression). No significant correlation was found for $\kappa$ light chains $(\mathrm{p}=0.079)$.

\section{Discussion}

The prevalence of renal involvement in patients with $\mathrm{MM}$ at the time of first diagnosis in this study was $41.8 \%$. The data given by others vary between 20 and 50\% [2, 16-18]. Renal function was significantly more impaired in MIDD at the time of diagnosis than in the other renal light chain diseases. A similar scenario was described in the largest study so far of patients with MIDD $(n=63)$ who presented with a mean creatinine level of $336 \mu \mathrm{mol} / \mathrm{l}$ at the time of diagnosis [19]. The proteinuria was lowest in MCN compared to AL and MIDD. However, a reliable differentiation between the three groups cannot be made by the degree of proteinuria. Another helpful tool in the differentiation between the various forms of renal im- pairment is the type of monoclonal protein. In $\mathrm{MCN}$, the type shows no significant difference ( $\kappa 55.2 \%, \lambda 44.8 \%$ ), whereas in MIDD, the light chain $\kappa$ is found more often ( $\kappa 83.3 \%, \lambda 16.6 \%$ ). In AL, this is true for the light chain $\lambda(\kappa 30 \%, \lambda 70 \%)[2,19,20]$. The reasons for this predominance in the different subgroups are not clear [21-23].

Our study showed that none of the screening tests investigated here were sensitive enough to accurately detect all the specific light chain-associated diseases. The free light test performed best with a sensitivity of only $71 \%$ for patients with MIDD, but reaching $100 \%$ in patients with AL. Possibly a combination of the immunofixation in serum and urine may produce better results.

One may assume that the degree of renal function may directly influence the concentration of light chains and a deterioration of renal function may therefore cause higher serum light chain concentrations. However, we found only a moderately significant $(p<0.05)$ correlation between eGFR and serum and urinary concentrations of $\lambda$ chains, but no significant effect was seen for $\kappa$ light chains or the $\kappa / \lambda$ ratios. Therefore, we believe that the degree of renal function is not a major contributing factor in our analysis.

The quantitative measurement of the light chain ratio in the urine may be used to distinguish patients with MCN from those with AL or MIDD. A quotient of $>20$ indicates MCN type $\kappa$, whereas a quotient of $<0.2$ is typical for MCN type $\lambda$. Patients with AL or MIDD usually show only moderately pathological levels of the light chain ratios in the urine.

Until now, urine protein analysis has mainly been used as a screening tool for renal involvement or as a prognostic marker [24, 25]. In a first study, the combination of a Bence-Jones proteinuria and a severe albuminuria was described as a hint for AL or MIDD [26]. In accordance with these data, only slightly elevated albuminuria or IgG excretion in the urine in the presence of a Bence-Jones proteinuria was an indicator for MCN in our study. In comparison, in AL or MIDD, urinary albumin and IgG excretion is significantly more enhanced and Bence-Jones proteinuria is low.

The high amount of glomerular filtrated light chains in MCN as well as the unselective proteinuria caused by the glomerular deposition of monoclonal proteins in MIDD or AL leads to an injury of the proximal tubules $[27,28] . \alpha_{1}$-Microglobulin in the urine as a marker for tubular injury was elevated in all four forms of renal manifestation. Therefore, $\alpha_{1}$-microglobulin excretion cannot be used for differential diagnosis and instead indicates injury to the tubulointerstitium. 
Since urinary protein findings in MCN are often typically as described above, it can be suggested that histological verification is not always necessary. However, renal prognosis as determined by tubulointerstitial injury and the potential of recovery can only be determined by renal biopsy. In addition, in patients for whom renal manifestation is the sole indication for chemotherapy (e.g. MM stage I with impaired renal function), a histological verification should be carried out to exclude other causes for the renal dysfunction. Furthermore, in patients with a glomerular-type proteinuria in combination with the presence of a monoclonal protein, a renal diagnosis based on only blood and urine protein parameters is not reliable. For the differential diagnosis between AL, MIDD, as well as other unrelated glomerular diseases, a histological verification is inevitable.
Arthur R. Bradwell, the pioneer who developed the free light chain assay $[29,30]$, also pointed out the potential advantage of this assay in the differential diagnosis of myeloma-associated renal disease $[31,32]$.

In summary, while methods for the detection of a monoclonal protein in patients with $\mathrm{MCN}$ have a very good sensitivity, they are only fairly sensitive in patients with AL or MIDD. A much better sensitivity in this regard could be shown by the quotient of the free light chains in serum. With urinary protein analysis (immunofixation, light chain ratios, urinary albumin and IgG excretion), MCN can be differentiated from AL and MIDD by noninvasive means.

\section{Disclosure Statement}

The authors have no conflicts of interest to disclose.

\section{References}

1 Haas M, Spargo BH, Wit EJ, Meehan SM: Etiologies and outcome of acute renal insufficiency in older adults: a renal biopsy study of 259 cases. Am J Kidney Dis 2000;35:433-447.

$\checkmark 2$ Kyle RA, Gertz MA, Witzig TE, Lust JA, Lacy MQ, Dispenzieri A, Fonseca R, Rajkumar SV, Offord JR, Larson DR, et al: Review of 1,027 patients with newly diagnosed multiple myeloma. Mayo Clin Proc 2003;78:2133.

-3 Knudsen LM, Hippe E, Hjorth M, Holmberg E, Westin J: Renal function in newly diagnosed multiple myeloma - a demographic study of 1,353 patients. The Nordic Myeloma Study Group. Eur J Haematol 1994;53:207212.

4 Kyle RA, Therneau TM, Rajkumar SV, Larson DR, Plevak MF, Melton LJ 3rd: Incidence of multiple myeloma in Olmsted County, Minnesota: trend over 6 decades. Cancer 2004;101:2667-2674.

5 Montseny JJ, Kleinknecht D, Meyrier A, Vanhille P, Simon P, Pruna A, Eladari D: Long-term outcome according to renal histological lesions in 118 patients with monoclonal gammopathies. Nephrol Dial Transplant 1998;13:1438-1445.

-6 Korbet SM, Schwartz MM: Multiple myeloma. J Am Soc Nephrol 2006; 17:2533-2545.

7 Ivanyi B: Renal complications in multiple myeloma. Acta Morphol Hung 1989;37:235243.

-8 Herrera GA, Joseph L, Gu X, Hough A, Barlogie B: Renal pathologic spectrum in an autopsy series of patients with plasma cell dyscrasia. Arch Pathol Lab Med 2004;128:875879.
$\$ 9$ Khamlichi AA, Aucouturier P, Silvain C, Bauwens M, Touchard G, Preud'homme JL, Nau F, Cogne M: Primary structure of a monoclonal $\kappa$ chain in myeloma with light chain deposition disease. Clin Exp Immunol 1992;87:122-126.

10 Sanders PW, Booker BB: Pathobiology of cast nephropathy from human Bence-Jones proteins. J Clin Invest 1992;89:630-639.

11 Solomon A, Weiss DT, Kattine AA: Nephrotoxic potential of Bence-Jones proteins. N Engl J Med 1991;324:1845-1851.

12 Solomon A, Weiss DT, Pepys MB: Induction in mice of human light-chain-associated amyloidosis. Am J Pathol 1992;140:629-637.

13 Gerth J, Wolf G: Nierenbiopsie: Indikation und Durchführung. Nephrologe 2008;3: 169-177.

14 Durie BG, Salmon SE: A clinical staging system for multiple myeloma. Correlation of measured myeloma cell mass with presenting clinical features, response to treatment, and survival. Cancer 1975;36:842-854

15 Levey AS, Bosch JP, Lewis JB, Greene T, Rogers N, Roth D: A more accurate method to estimate glomerular filtration rate from serum creatinine: a new prediction equation. Modification of Diet in Renal Disease Study Group. Ann Intern Med 1999;130:461-470.

16 Alexanian R, Barlogie B, Dixon D: Renal failure in multiple myeloma. Pathogenesis and prognostic implications. Arch Intern Med 1990;150:1693-1695.
17 Eleutherakis-Papaiakovou V, Bamias A, Gika D, Simeonidis A, Pouli A, Anagnostopoulos A, Michali E, Economopoulos T, Zervas $\mathrm{K}$, Dimopoulos MA: Renal failure in multiple myeloma: incidence, correlations, and prognostic significance. Leuk Lymphoma 2007;48:337-341.

18 Dimopoulos MA, Kastritis E, Rosinol L, Blade J, Ludwig H: Pathogenesis and treatment of renal failure in multiple myeloma. Leukemia 2008;22:1485-1493.

19 Pozzi C, D’Amico M, Fogazzi GB, Curioni S, Ferrario F, Pasquali S, Quattrocchio G, Rollino C, Segagni S, Locatelli F: Light chain deposition disease with renal involvement: clinical characteristics and prognostic factors. Am J Kidney Dis 2003;42:1154-1163.

20 Gertz MA, Leung N, Lacy MQ, Dispenzieri A, Zeldenrust SR, Hayman SR, Buadi FK, Dingli D, Greipp PR, Kumar SK, et al: Clinical outcome of immunoglobulin light chain amyloidosis affecting the kidney. Nephrol Dial Transplant 2009;10:3132-3137.

-21 Poshusta TL, Sikkink LA, Leung N, Clark RJ, Dispenzieri A, Ramirez-Alvarado M: Mutations in specific structural regions of immunoglobulin light chains are associated with free light chain levels in patients with $\mathrm{Al}$ amyloidosis. PLoS ONE 2009;4:e5169.

-22 Randles EG, Thompson JR, Martin DJ, Ramirez-Alvarado M: Structural alterations within native amyloidogenic immunoglobulin light chains. J Mol Biol 2009;389:199-210.

23 Sikkink LA, Ramirez-Alvarado M: Biochemical and aggregation analysis of BenceJones proteins from different light chain diseases. Amyloid 2008;15:29-39. 
24 Corso A, Serricchio G, Zappasodi P, Klersy C, Bosoni T, Moratti R, Castagnola C, Lazzarino M, Pagnucco G, Bernasconi C: Assessment of renal function in patients with multiple myeloma: the role of urinary proteins. Ann Hematol 1999;78:371-375.

-25 Corso A, Zappasodi P, Pascutto C, Bosoni T, Mangiacavalli S, Lorenzi A, Rusconi C, Lazzarino M: Urinary proteins in multiple myeloma: correlation with clinical parameters and diagnostic implications. Ann Hematol 2003;82:487-491.

26 Melmed GM, Fenves AZ, Stone MJ: Urinary findings in renal light chain-derived amyloidosis and light chain deposition disease. Clin Lymphoma Myeloma 2009;9:234-238.
27 Madalena L, Facio ML, Angerosa M, Pandolfo M, Bresciani P, Alejandre M, Pizzolato M, Toblli JE: Urinary excretion of low molecular weight proteins in patients with pure monoclonal light chain proteinuria. J Nephrol 2007;20:683-688.

28 Batuman V: Proximal tubular injury in myeloma. Contrib Nephrol. Basel, Karger, 2007, vol 153, pp 87-104.

29 Bradwell AR, Carr-Smith HD, Mead GP, Harvey TC, Drayson MT: Serum test for assessment of patients with Bence-Jones myeloma. Lancet 2003;361:489-491.

30 Bradwell AR, Harding SJ, Fourrier NJ, Wallis GLF, Drayson MT, Carr-Smith HD, Mead GP: Assessment of monoclonal gammopathies by nephelometric measurement of individual immunoglobulin $\kappa / \lambda$ ratios. Clin Chem 2009, 55:1646-1655.
31 Hutchison CA, Plant T, Drayson M, Cockwell P, Kountouri M, Basnayake K, Harding S, Bradwell AR, Mead G: Serum-free light chain measurement aids the diagnosis of myeloma in patients with severe renal failure. BMC Nephrology 2008;9:11.

32 Hutchison CA, Harding S, Hewins P, Mead GP, Townsend J, Bradwell AR, Cockwell P: Quantitative assessment of serum and urinary polyclonal free light chains in patients with chronic kidney disease. Clin J Am Soc Nephrol 2008;3:1684-1690. 